\title{
Ensino Remoto Emergencial durante a pandemia da COVID-19: A visão dos professores de escolas de línguas de Curitiba sobre 0 ensino com crianças
}

\author{
Andréa Duarte Ross ${ }^{1}$ \\ Andressa Mara Dahmer ${ }^{2}$ \\ Fabiana Maria Bora Medeiros ${ }^{3}$ \\ Cláudia Beatriz Monte Jorge Martins ${ }^{4}$
}

\section{RESUMO}

Este artigo analisa como professores de escolas de língua inglesa de Curitiba utilizam o formato Ensino Remoto Emergencial (ERE) durante a pandemia da COVID-19, especificamente para alunos de 06 a 10 anos. Esta é uma pesquisa descritiva do tipo levantamento, que coletou dados sobre a visão dos professores e as estratégias utilizadas durante o ERE. Foram identificadas as medidas tomadas nas primeiras semanas; as dificuldades técnicas, pedagógicas e pessoais; a relação dos professores com a tecnologia e as estratégias utilizadas ou adaptadas para o ensino com crianças na faixa etária estipulada. O ERE possibilitou aos professores adquirirem novas habilidades ou adaptarem as que já possuíam e incentivou o uso da tecnologia. Essa medida, contudo, precisa de aprimoramento e mais capacitações.

Palavras-chave: Ensino Remoto Emergencial. Ensino de Línguas. Tecnologia. Pandemia. Ensino de crianças.

\footnotetext{
11andreaross@alunos.utfpr.edu.br - Universidade Tecnológica Federal do Paraná

2 adahmer@alunos.utfpr.edu.br - Universidade Tecnológica Federal do Paraná

3 fabianamedeiros@alunos.utfpr.edu.br - Universidade Tecnológica Federal do Paraná

${ }^{4}$ claudiab@utfpr.edu.br - Universidade Tecnológica Federal do Paraná
} 


\section{Emergency Remote Teaching during the COVID-19 pandemic: the view of language school teachers in Curitiba on teaching children}

\section{ABSTRACT}

This paper analyzes how teachers at English language schools in Curitiba use the Emergency Remote Teaching (ERT) format during the COVID19 pandemic, specifically for students aged 6 to 10 years old. This is a descriptive-survey research that collected data on teachers' views and strategies used during ERT. Results identified the measures taken in the first weeks; the technical, pedagogical, and personal difficulties; teachers' relationship with technology, and the strategies used or adapted for teaching children of the stipulated age rage. ERT enabled teachers to acquire new skills or adapt those they already had and encouraged the use of technology. This emergency teaching mode, however, needs improvement and more teacher training.

Keywords: Emergency Remote Teaching. Language Teaching. Technology. Pandemic. 


\section{INTRODUÇÃO}

O ano de 2020 será lembrado na história pela pandemia da COVID-19. Inicialmente, a COVID-19 foi identificada em uma província da China no final de 2019. O país teve que adotar medidas rigorosas para conter a epidemia da doença, no entanto, rapidamente, o vírus se espalhou para diversos países. Em março de 2020, a Organização Mundial da Saúde (OMS) declarou a Europa como o novo epicentro da pandemia, por ter números de casos e mortes maiores que o relatado no resto do mundo. Em abril do mesmo ano, a OMS informou que mais de um milhão de casos da doença tinham sido confirmados (OMS, 2020). A situação no Brasil também teve um rápido agravamento, haja vista que em março do mesmo ano foram registrados os primeiros casos e as primeiras mortes (JOHNS HOPKINS, 2020).

Ainda em março de 2020, diversos países declararam quarentena e criaram medidas para que pudessem evitar a contaminação da população: foram fechados estabelecimentos comerciais e de entretenimento; restaurantes e bares tiveram a capacidade diminuída para atendimento presencial; eventos foram adiados e fronteiras foram fechadas. Em relação às escolas, foram tomadas diferentes abordagens sobre a suspensão das aulas. Os Estados Unidos optaram por manter as aulas e realizar o fechamento das escolas de acordo com o aumento de casos; a Suécia decidiu manter as escolas abertas por motivos financeiros; e cerca de 150 países, como França, Alemanha e Peru, optaram pelo fechamento total (GALLAS, 2020; BANCO MUNDIAL, 2020).

No Brasil, foi escolhido o fechamento total das instituições de ensino, havendo assim a suspensão das aulas presenciais. O Ministério da Educação (MEC) propôs alternativas para a continuação do ano letivo, com aulas à distância sendo transmitidas aos alunos por meio de programas de televisão e rádio, videoaulas, etc.

Os meios encontrados para manter as aulas, mas de forma não presencial, encaixam-se no que é chamado de Ensino Remoto Emergencial (ERE) e possui aspectos diferentes da Educação a Distância (EaD). O objetivo do ERE é manter o acesso dos alunos às instruções e ao ensino que estariam previamente planejados para o modo presencial ou híbrido. As soluções utilizadas fornecem o acesso rápido e confiável durante um período de crise ou emergência (HODGES et al., 2020).

O Ensino Remoto pode surtir efeito negativo no desenvolvimento das crianças menores, uma vez que não devem sofrer exposição excessiva às telas de aparelhos como TV, celulares e tablets. $O$ uso desses aparelhos por crianças entre 6 e 10 anos deve ser limitado para 1 a 2 horas ao dia (SBP, 2020). A necessidade de um adulto para supervisionar o aprendizado na Educação Infantil é indiscutível, além de que a falta do ambiente escolar influencia diretamente na concentração para cumprimento das atividades propostas, já que o Ensino Infantil se dá por meio de interações e experiências, como apresentado pelo Núcleo Ciência pela Infância (NCPI, 2020).

Compreendendo o ERE e as adversidades da crise mundial, buscaram-se respostas e soluções em todos os lugares do mundo, mas se pode começar a entender essa situação no local em que se está, na cidade em que se vive. Identificar as mudanças ocorridas nesse período único da humanidade pode auxiliar em futuras situações e trazer avanços para o ensino. Uma das 
recomendações feitas pela UNESCO (2020) para enfrentar esse momento foi "reimaginar" a educação e acelerar mudanças positivas no ensino e aprendizado.

As escolas brasileiras de línguas, assim como as demais instituições de ensino, também tiveram que enfrentar essa crise como tudo o que se relaciona à educação. Porém, há diferenças significativas, como o fato de não serem atividades obrigatórias regulares, e sim atividades extras, que são aquelas que sofrem os primeiros cortes dos orçamentos em momentos de crise. Não podiam, portanto, suspender as atividades, considerando que, ao não oferecerem o seu serviço, corriam o risco de terem que fechar as instituições definitivamente. Careciam, assim, de um meio para que as aulas continuassem sendo ministradas durante a pandemia. Outras diferenças dessas escolas com o ensino regular público e privado são o número de aulas, a inexistência de ano letivo, o menor número de alunos em sala de aula, as metodologias aplicadas, etc. (MARTINS, 2002). Por suas características únicas, diversas escolas de línguas optaram por aderir ao ERE.

Considerando esse contexto, este artigo tem como objetivo analisar as estratégias utilizadas por professores de escolas de língua inglesa de Curitiba durante as aulas de ERE na pandemia da COVID-19, especificamente para alunos da faixa etária de 06 a 10 anos. Busca-se também comparar essas soluções com as alternativas utilizadas em outros países para o ERE e descrever as principais dificuldades encontradas.

Esta é uma pesquisa descritiva do tipo levantamento quantitativo que faz uso de um questionário como instrumento de coleta. O questionário foi elaborado pela plataforma Google Forms e ficou disponível por um curto período em setembro de 2020. Com esse instrumento, foi possível coletar a visão dos professores sobre o ERE, as soluções e atitudes tomadas nas primeiras semanas, as dificuldades, o uso da tecnologia, etc.

O presente estudo coletou dados que descrevem um período único, em que a sociedade foi obrigada a se modificar. Conhecer as estratégias, soluções adotadas e as inovações feitas é importante para se aprofundar em como foi mantido o ensino nesse período peculiar. Além disso, em um momento de crise ou dificuldade, podem surgir inovações e novas percepções. Pesquisas sobre o tema e o momento atual são fundamentais para um registro do que aconteceu e ajudarão futuros estudos que abordem a mesma temática.

As inovações adotadas no contexto desta pandemia poderão ser aprimoradas e auxiliar na formação de futuros professores de língua inglesa e de outras disciplinas, que ensinarão crianças já acostumadas com as tecnologias e seus dispositivos. Esses futuros alunos serão uma geração marcada pela pandemia e pelo que surgir neste período de crise. Além disso, estudiosos discorrem sobre a inevitabilidade de novas pandemias (BBC NEWS BRASIL, 2020), com as quais será possível para profissionais da área educacional já estarem preparados a partir das experiências e informações coletadas neste momento.

Este artigo irá primeiramente apresentar informações sobre o contexto das escolas de línguas, a definição de ERE e seu desenvolvimento no Brasil e no mundo. Na sequência relata a metodologia adotada para a pesquisa, os resultados e discussão.

\section{ESCOLAS DE LÍNGUAS}

No Brasil, há a crença de que o inglês ensinado nas escolas regulares não é suficiente para o aluno se comunicar ou ter o conhecimento necessário para seu futuro. Segundo Walker (2005), 
essa crença traz ao menos quatro efeitos importantes para o cenário de ensino de língua inglesa no país. São eles:

a) $O$ inglês do Ensino Médio é geralmente tratado como inglês para o exame de ingresso à universidade - competências gramaticais e/ou IPE/leitura.

b) As Universidades e Secretarias Estaduais de Educação sentem-se encorajadas a criar os seus próprios institutos de ensino de línguas para estudantes do setor público e/ou para a comunidade.

c) A ideia de que não se pode esperar que o sistema escolar ensine com eficácia a comunicação em inglês contribui para o extraordinário sucesso do setor privado de escolas de língua inglesa.

d) Os Parâmetros Curriculares Nacionais (PCNs), produzidos em 1998 para orientar os professores de línguas estrangeiras em seu planejamento, sugerem que, realisticamente, os professores devem se concentrar nas habilidades de leitura, já que geralmente não é possível ensinar de forma comunicativa na sala de aula da escola (WALKER, 2005, p. 21, tradução nossa).

Com esse panorama, a crença da má qualidade do ensino nas escolas regulares e pensando nas oportunidades de emprego e na vantagem que a língua inglesa pode trazer profissionalmente, muitos pais optam por complementar os estudos de seus filhos matriculandoos em escolas de línguas, ou mais especificamente de inglês. Dessa forma, as crianças ocupam seu tempo e o aprendizado trará frutos no futuro (WALKER, 2005, p. 40).

Segundo Walker (2005), é possível dividir essas escolas entre escolas de qualidade e escolas de franquia. A autora define as escolas de qualidade como aquelas que fazem uso de materiais e livros importados. Essas instituições optam por investir no treinamento e desenvolvimento de seus professores e dessa forma podem manter um alto nível de autonomia educacional (WALKER, 2005). As escolas de franquia são aquelas que vendem sua franquia pelo país para quem estiver interessado em investir em escolas de línguas. 0 material é nacional e tem a marca da franquia que oferece o suporte pela sede, podendo ser insignificante. Os padrões de administração e de ensino dependem das características do franqueado (WALKER, 2005).

Além disso, segundo a Associação Brasileira de Franquias (ABF, 2020), as franquias de ensino de idiomas faturam mais de $\mathrm{R} \$ 35$ milhões ao ano, mostrando ser um grande mercado no país. Não há dados indicando o formato das aulas ofertadas pelas franquias, porém a realidade mostra a maioria como sendo no modelo presencial.

Com a pandemia, o mercado das escolas de línguas foi grandemente afetado, já que houve a necessidade da suspensão da oferta do serviço prestado: as aulas presenciais canceladas pelo governo em todo o país. Isso gerou preocupação sobre como dar continuidade às aulas, pois ocasionaria um problema financeiro para as escolas de língua. Por ser uma atividade extracurricular, tornam-se a primeira despesa a ser cortada quando há alguma crise financeira e ao não ofertarem o serviço não terão como receber por isso.

O caos causado pela pandemia fez as escolas de línguas buscarem alternativas e as aulas on-line foram adotadas por várias delas como solução para manter as matrículas ativas (GRATÃO, 2020). Essa solução começou a partir de iniciativas individuais de alguns franqueados e posteriormente foram seguidas pelos demais, com o prolongamento da suspensão das aulas presenciais. Essas aulas on-line seguiram o formato do ERE, que será detalhado na sequência. 
Houve a possibilidade de interação dos alunos por meio de videoconferência, e, para as crianças, aconteceram adaptações; houve a simplificação da realidade física para a aula on-line, com a intenção de que as atividades propostas conseguissem manter a afetividade entre professores e alunos, não se limitando ao envio de materiais aos pais.

\section{ENSINO REMOTO EMERGENCIAL (ERE)}

Hodges et al. (2020) definem ERE como:

[...] uma mudança curricular temporária e alternativa devido a circunstâncias de crise. Envolve a utilização de soluções exclusivamente remotas de ensino para instrução ou educação que em outra condição seria ministrada presencialmente ou em formato híbrido e que retornarão ao formato original assim que a crise emergencial diminuir (HODGES et al., 2020, tradução nossa).

O ERE é algo não planejado previamente. As soluções adotadas são temporárias, usadas durante a crise e para evitar que nada seja feito: "temos que ser capazes de pensar fora dos padrões para gerar várias possibilidades de solução que ajudem a atender às novas necessidades dos estudantes e comunidades" (HODGES et al., 2020). Com isso, o meio escolhido para realização do ERE não precisa ser on-line, podendo ser realizado por meio de rádio, TV e materiais impressos, ou outro material mais adequado à situação.

Considerando a aplicação dessa forma de ensino, há a urgência da adaptação profissional para que os professores desenvolvam as habilidades necessárias para trabalhar e ministrar as aulas em um ambiente on-line. Existe, entretanto, também a preocupação voltada ao aprendizado dos alunos, a eficácia dos conteúdos e de que modo mantê-los aplicados nas atividades e aulas "e isso é difícil de ser feito a distância sem que haja um trabalho de redesenho e adaptação curricular, em especial, com crianças” (BLIKSTEIN et al., 2020).

Pelo fato de o ERE ser realizado a distância pode ocorrer uma confusão com a EaD, que é definida como uma modalidade educacional em que o processo de ensino e aprendizagem se dá com o uso de meios e tecnologias da informação e comunicação. Os alunos e professores se encontram em lugares e tempos diferentes (BRASIL, 2017). Entre as características dessa modalidade estão: o planejamento antecipado e a carga horária adaptada ao modelo à distância. Além disso, a EaD é efetiva de acordo com a necessidade do discente, geralmente adultos que têm o objetivo do estudo à distância e alunos que possuem um perfil autônomo. O papel do professor é compartilhado entre tutores e professores, em alguns casos pode ter a figura de um professor presencial. (JOYE; MOREIRA; ROCHA, 2020).

A partir dessa diferenciação se consegue entender melhor como funciona o ERE, quais as possibilidades para a sua realização, e as soluções encontradas dependem do contexto de ensino em cada país e das condições de seus alunos, o que será explicado a seguir.

\subsection{ERE ao redor do mundo}

No mundo, foram escolhidas diferentes formas de aplicar atividades e usos de tecnologias para manter o ERE. Segundo a UNICEF: 
Para cada nível de educação, a maioria dos países desenvolveu políticas relativas à aprendizagem remota digital (baseada na Internet) ou por transmissão (baseada na televisão ou rádio). A abordagem mais comum focou a instrução digital, que foi utilizada por $42 \%$ dos países para a Educação Infantil, $74 \%$ dos países para os anos iniciais do Ensino Fundamental e $77 \%$ dos países para os anos finais do Ensino Fundamental e o Ensino Médio. Muitos países também desenvolveram currículos de transmissão, especialmente para estudantes do Ensino Fundamental (UNICEF, 2020, p. 03, tradução nossa).

Cada país adotou uma forma de ERE que fosse mais adequada e viável às suas condições. Uma notícia de abril publicada no site Escolas Exponenciais (2020) mostra como ocorreu o ERE na Europa. Em Portugal, por exemplo, as aulas foram suspensas para os alunos desde a Educação Infantil até as universidades, e o ano letivo continuou por meio de plataformas on-line. Na Suíça e na França, as tarefas da Educação Infantil foram enviadas por e-mail aos pais, com introdução e explicações dos professores. Na Inglaterra, os conteúdos foram disponibilizados nos sites das escolas, não tendo uma plataforma específica para aulas on-line (ESCOLAS EXPONENCIAIS, 2020).

Apesar de soluções criativas e fora do ambiente on-line, segundo a ONU (2020), em documento de agosto de 2020 sobre a educação durante a COVID-19, as plataformas on-line foram a opção mais escolhida pelos países para o ERE nos diferentes níveis educacionais. $\mathrm{Na}$ América Latina e Caribe, entretanto, o ERE por meio de materiais impressos foi empregado em mais de $60 \%$ para os anos iniciais do Ensino Fundamental, ultrapassando o uso da televisão com cerca de 50\% (ONU, 2020, p. 13).

No Brasil, foi adotado o fechamento total das escolas. Com isso, escolas públicas e privadas, universidades e outras instituições de ensino, como cursos profissionalizantes e escolas de línguas, foram proibidos de funcionar com aulas presenciais. Optaram, então, por outros meios para manterem as aulas.

Entre as alternativas indicadas pelo MEC, estão as videoaulas, as plataformas virtuais, as redes sociais, os programas de televisão e rádio e os materiais impressos entregues aos responsáveis (BRASIL, 2020). Para as redes públicas estaduais, o governo paranaense, por exemplo, ofereceu aulas em canais de TV aberta, assim os alunos conseguem acompanhar o conteúdo pela televisão gratuitamente, sendo possível acompanhar as transmissões também na plataforma de compartilhamento de vídeos e no Youtube (PARANÁ, 2020).

\subsection{Efeitos do ERE para professores e alunos no Brasil}

O ERE alterou o espaço e a aula em si, trazendo efeitos para alunos e professores. Diversos profissionais tiveram suas rotinas e trabalhos alterados. O Instituto Península (2020a) está realizando uma pesquisa intitulada Sentimento e percepção dos professores brasileiros nos diferentes estágios do coronavírus no Brasil, que pretende ouvir os profissionais da Educação até o fim da crise relacionada à COVID-19. Conforme mostra a Figura 1 abaixo, a pesquisa foi dividida em quatro estágios:

\section{Figura 1: Estágios da pesquisa do Instituto Península}




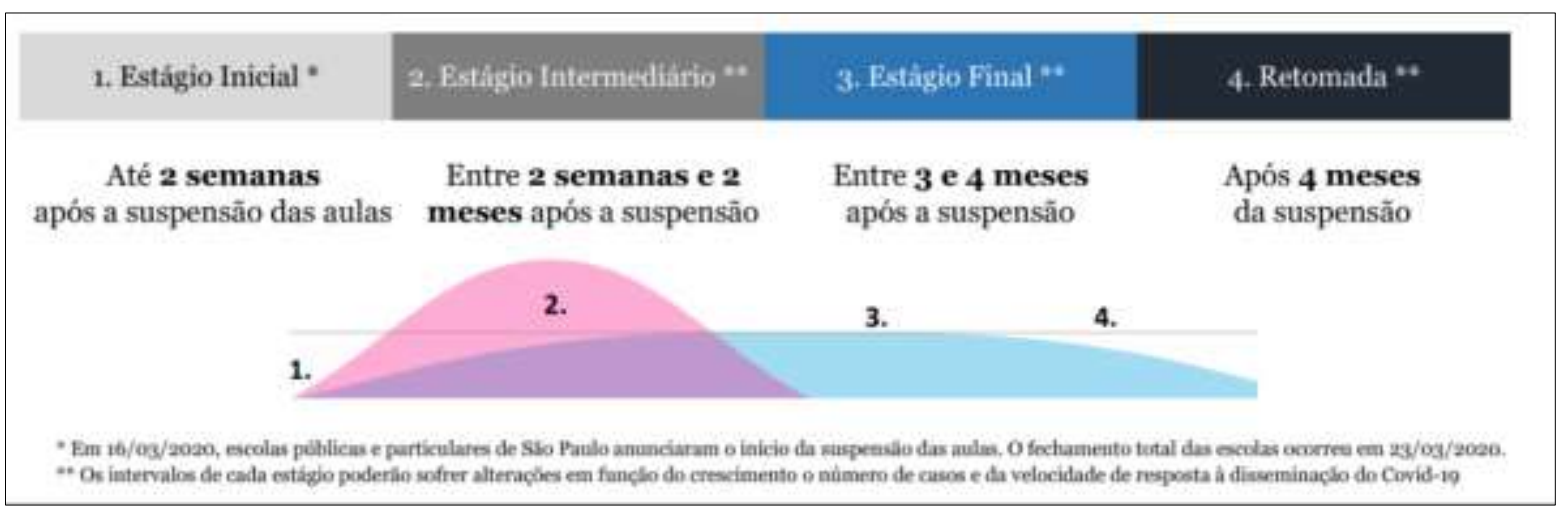

Fonte: Instituto Península, 2020a.

Esse estudo tem como objetivo compreender o panorama que cerca os educadores no Brasil. Já foram entrevistados mais de 7 mil professores das redes municipais, estaduais e particulares do Ensino Infantil ao Ensino Médio de todo o Brasil.

A primeira etapa realizada logo após a suspensão das aulas mostra alterações na rotina e na saúde mental desses profissionais, assim como uma preocupação com a saúde de familiares (INSTITUTO PENÍNSULA, 2020a).

A segunda etapa apresenta importantes informações relacionadas ao ensino: $88 \%$ dos professores participantes afirmaram que antes da paralisação das aulas presenciais nunca haviam dado aulas a distância de forma remota. E cerca de $83 \%$ se sentiam pouco ou não preparados para o Ensino Remoto (INSTITUTO PENÍNSULA, 2020b).

A terceira etapa da pesquisa aprofunda os desafios e outras questões relacionadas ao Ensino Remoto. Entre os resultados, estão os principais desafios enfrentados pelos professores, como a falta de infraestrutura e a dificuldade com engajamento dos alunos (INSTITUTO PENÍNSULA, 2020c). Essas são algumas das percepções da situação atual dos educadores no Brasil obtidas com a pesquisa, as quais são importantes para este momento do ensino e aprendizagem e que embasarão o presente estudo.

Com relação às crianças do século XXI, é importante destacar que elas são inseridas na sociedade digital precocemente. De acordo com uma pesquisa realizada pela AVG Technologies em 2014, um total de $69 \%$ das crianças usa primeiro um computador para depois aprender as atividades simples como amarrar os cadarços (ANSCOMBE, 2014). Como consequência, desenvolvem habilidades nesses meios tecnológicos desde jovens. Não obstante, o letramento digital para crianças se tornou essencial para que sejam acolhidas e integradas nesse meio e, então, com o auxílio de sua família, consigam realizar as atividades que serão propostas pelos professores. A adesão de crianças ao ERE, entretanto, vem sendo destacada pela dificuldade da criação de um projeto pedagógico que se adeque às adversidades do Ensino à Distância, pois "a saudade do ambiente escolar e dos colegas têm deixado muitos alunos desanimados na hora de fazer atividades acadêmicas em casa" (DEREVECKI, 2020).

Apesar das dificuldades encontradas para a adoção do ERE, uma das consequências é que a tecnologia está adentrando as salas de aulas de maneira efetiva, podendo assim se manter após a pandemia. Garofalo (2020) afirma: 
E com aulas mediadas pelas tecnologias, abriu-se uma série de discussões acerca de aulas com interatividade, metodologias ativas e atrativas aos estudantes, já que a interação não é presencial e requer muita atratividade para envolver os mesmos (GAROFALO, 2020).

Além disso, o professor precisou se adaptar, tendo que se reinventar em pouco tempo. A tecnologia se integrou a metodologia deles e "com isso, os contatos constantes com essas despertam no professor a vontade de continuar incorporando tais métodos mesmo no período pós-pandemia" (FARIAS et al., 2020, p. 8).

Compreendendo a situação das escolas de línguas no Brasil e o conceito do ERE, é possível entender a adoção desse modelo de ensino pelas escolas de línguas, pois, com esse período especial, viu-se a necessidade de buscar uma alternativa para a continuidade das aulas. Ainda existe a questão de trabalhar com crianças em um período de alfabetização que necessita da interação para um melhor resultado. Pelo momento único que está acontecendo, ainda são poucas as pesquisas que abordam esse tema tão específico, fazendo com que a presente pesquisa seja uma das pioneiras sobre o tópico.

\section{METODOLOGIA}

Esta é uma pesquisa descritiva do tipo levantamento quantitativo, que faz uso de um questionário como instrumento de coleta. Segundo Gil (2002), pesquisas descritivas têm o objetivo de descrever as características ou a situação de uma população, podendo também estabelecer relações entre diferentes variáveis; utilizam técnicas padronizadas de coleta de dados, como questionários. O levantamento consiste na "interrogação direta das pessoas cujo comportamento se deseja conhecer" (GIL, 2002, p. 50). São coletadas informações de uma parcela do grupo pesquisado para então realizar uma análise quantitativa e obter conclusões sobre esses dados (GIL, 2002). A pesquisa realizada encaixa-se nessas classificações, pois se busca descrever a situação de um grupo específico de pessoas, os professores de línguas da cidade de Curitiba. Assim, ao se levantar as informações sobre esse grupo, pode-se analisar e obter conclusões de suas experiências durante o ERE.

O objeto desta pesquisa são os professores das escolas de inglês da cidade de Curitiba que dão aula a alunos de 06 a 10 anos. A escolha da faixa etária se deu pela correspondência aos anos iniciais do Ensino Fundamental, em que ocorre a alfabetização e uma série de habilidades que devem ser desenvolvidas com as crianças, como o "desenvolvimento do aprender, a aquisição de conhecimentos e habilidades e a compreensão do ambiente natural e social, da tecnologia e das artes" (BRASIL, 1996). Desse modo, é uma faixa etária que, pelo seu diferencial infantil apresentado, possui um enorme potencial de ser explorado, destacando as dificuldades existentes ao ministrar aulas para essas crianças.

As informações sobre o total de escolas de inglês na cidade de Curitiba não são de fácil acesso. Não foi possível encontrar documentos ou organizações que mostrassem dados sobre a quantidade dessas escolas na cidade por serem classificadas como cursos livres; esses estabelecimentos de ensino não são regidos pelo $\mathrm{MEC}$, sendo assim, também não há documentação nacional. A consulta on-line, em novembro de 2020 , com as palavras-chaves "escolas de línguas" + Curitiba trouxe 3.400 .000 resultados; com "escolas de idiomas" + Curitiba 
trouxe 112.000 resultados; e com "escolas de inglês" + Curitiba trouxe 133.000 resultados. Devido ao pouco tempo para a realização do estudo, não seria possível verificar e confirmar quais são as instituições que ofertam o ensino de inglês, se ainda estão em funcionamento, bem como eliminar as escolas repetidas, entre outras ações necessárias.

Sem esse total de escolas não é possível chegar também ao total de professores foco deste estudo. Considerando essa dificuldade e a questão do tempo escasso, a estratégia adotada, então, foi a amostragem por conveniência. Segundo Moreira e Caleffe (2006, p. 180), essa amostragem baseia-se no critério "fazer o que é mais rápido e conveniente'." Optou-se por enviar o questionário para professores de inglês que as pesquisadoras conhecessem; divulgar em grupos de professores; e também enviar para algumas escolas de inglês da cidade.

Os dados da presente pesquisa foram coletados por meio de um formulário on-line elaborado na plataforma Google Forms. Para a elaboração das questões, foi utilizada como referência a pesquisa Sentimento e Percepção dos Professores Brasileiros nos diferentes estágios do Coronavírus no Brasil, realizada pelo Instituto Península (2020a; 2020b; 2020c). Além disso, as pesquisadoras com a orientadora fizeram alterações e sugestões para que se atingisse o propósito do estudo.

Sendo este um trabalho de pequena escala e com pouco tempo para a sua realização, não foi verificada a validade ou a confiabilidade do questionário, assim como também não foi realizado o teste-piloto. No entanto, o questionário foi enviado para os demais participantes do Grupo de Pesquisa do qual as pesquisadoras participaram para que pudessem verificar algum problema, bem como fazer sugestões. 0 instrumento final ficou com 45 questões, sendo 39 fechadas e 6 abertas. 0 formulário ficou disponível para receber respostas no período de 22 a 28 de setembro de 2020.

\subsection{Limitações}

A presente pesquisa foi realizada alguns meses após o início da pandemia, o que trouxe uma série de limitações.

Inicialmente foram encontradas poucas publicações acadêmicas sobre a temática pesquisada. As informações estavam presentes em notícias e documentos veiculados por organizações, institutos nacionais e internacionais, em grande parte publicadas em sites on-line. Apesar de existirem artigos ou ensaios sobre a COVID-19 anteriores à realização da pesquisa, estes não focavam a educação ou ensino. Além de que, parte das produções, abordavam o ensino regular, que possui características distintas em relação ao objeto pesquisado. Outra limitação encontrada foi a busca de informações sobre as escolas brasileiras de línguas. Como já apontado anteriormente, essas instituições não são reguladas pelo MEC, portanto não há um órgão nacional que possua os dados sobre esse grupo. Essa dificuldade também aconteceu ao se buscar informações em escala estadual e municipal.

Apesar das limitações do instrumento de coleta de dados e da estratégia de amostragem usada, espera-se que com os resultados aqui obtidos este questionário possa servir de piloto para a aplicação de futuros instrumentos. 


\section{RESULTADOS E DISCUSSÃO}

\subsection{Perfil do Público-alvo}

Das 20 pessoas participantes, apenas 11 encaixam-se nas delimitações da pesquisa, e estão representadas por nove mulheres $(81,8 \%)$ e dois homens $(18,2 \%)$. Em relação à faixa etária dos participantes, 5 professores têm entre 19 e 24 anos (45,5\%); 3 entre 25 e 35 anos (27,3\%); e 3 com mais de 35 anos (27,3\%). Desses, 6 estão no estágio inicial da carreira - 0 a 3 anos de atividade e 5 estão no estágio intermediário - 6 a 12 anos (MOREIRA, 1995). Todos os participantes responderam que trabalham em uma franquia e atuavam em apenas uma escola em março de 2020.

Figura 2: Métodos de Ensino

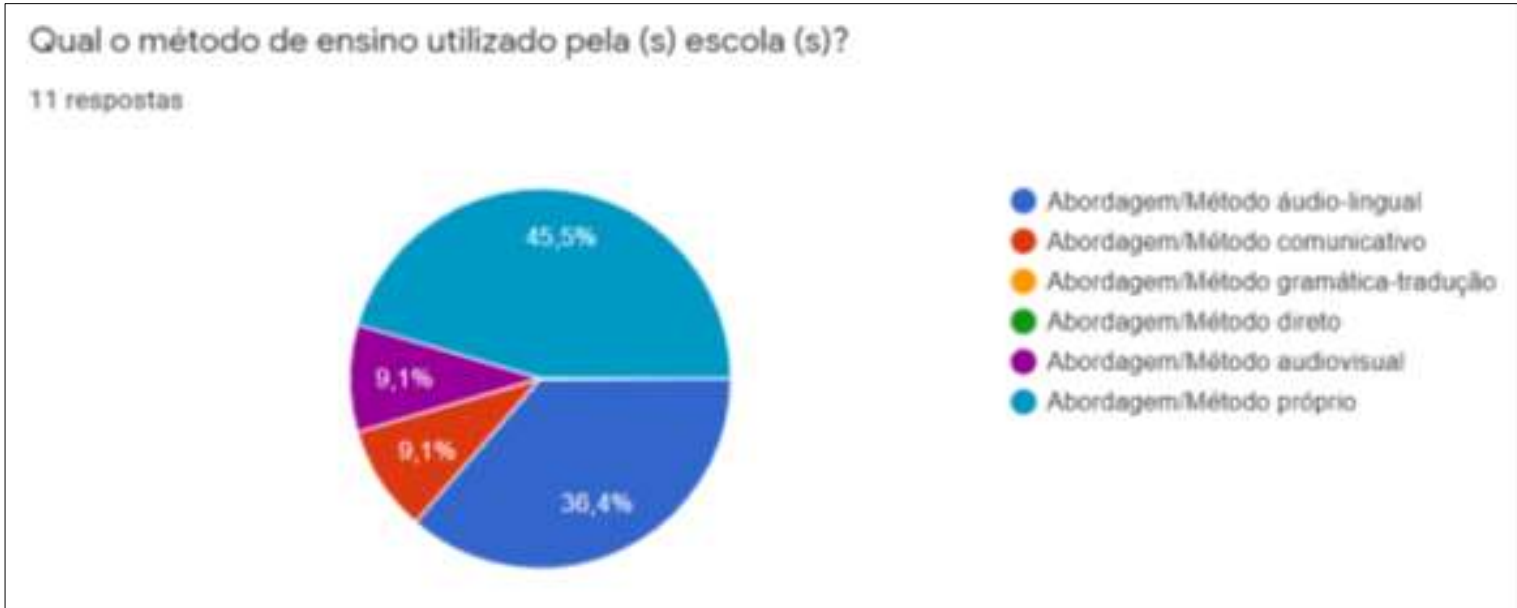

Fonte: Elaborado pelas autoras com base na pesquisa realizada, 2020.

\subsection{Métodos e modelos de aula}

Sobre o formato de aulas adotado previamente à pandemia por cada franquia, os resultados foram $81,8 \%$ para aulas apenas presenciais e $63,6 \%$ para aulas on-line. Entre os métodos de ensino das escolas, o método áudio-lingual e método próprio de cada franquia foram os mais representativos, como apresentado na Figura 2. Apesar disso, quando questionados sobre as faixas etárias do público-alvo das franquias, foram 9 respostas para todas as faixas etárias (81,8\%) e somente 2 respostas para crianças e adolescentes (18,2\%).

\subsection{Primeiras semanas de ERE}

As questões que abordaram as soluções, suportes e dificuldades foram divididas em duas seções: primeiras semanas de ERE e dificuldades. Dessa forma, foi possível entender os aspectos da mudança para o ERE, e como se desenvolveram as primeiras semanas.

No primeiro momento, os entrevistados responderam somente sobre os procedimentos que necessitaram de uma mudança imediata para que as franquias continuassem funcionando. 
Sobre a primeira atitude tomada pelas escolas após a suspensão das aulas: $36,4 \%$ tomaram a decisão sem consultar professores ou pais; $36,4 \%$ entraram em contato com pais e professores para decidir soluções conjuntamente; $18,2 \%$ consultaram apenas os professores para decidir os passos seguintes; e 9,1\% afirmaram que a decisão foi tomada pela franqueadora, criando um grupo provisório no WhatsApp com pais e professores para o envio de atividades extras.

Nessa seção, também foi perguntado quais foram as soluções adotadas, sendo possível assinalar mais de uma resposta. Os resultados mostraram que $90,9 \%$ das escolas optaram por aulas virtuais síncronas no mesmo horário das aulas presenciais; $81,8 \%$ afirmaram que foi mantido o uso do mesmo material das aulas presenciais nas aulas síncronas e assíncronas; $63,6 \%$ indicaram a criação de um ambiente virtual de ensino e aprendizado (AVEA) próprio da franquia; 36,4\% adotaram um AVEA já existente; $18,2 \%$ realizaram e postaram atividades escritas no AVEA adotado e $9,1 \%$ tiveram aulas virtuais assíncronas com aulas gravadas previamente e postada no AVEA escolhido.

Com a indicação das soluções adotadas, pode-se compreender que ocorreram diferentes formas de adoção do ERE. Destaca-se a resposta sobre os materiais didáticos para as aulas de ERE: "este foi o mesmo utilizado no ensino presencial", mostrando que não houve adaptação para um formato de ensino diferente. Essa permanência do material pode ter ocorrido por diversos motivos, como, por exemplo, a questão financeira, pois se evita o gasto com um novo material, o que poderia não ser bem visto por pais e alunos e resultar em cancelamentos.

$\mathrm{Na}$ mesma seção, os professores também puderam expressar suas dificuldades e inseguranças com o ERE nas primeiras semanas, mostrando que 10 dos 11 professores nunca haviam ministrado aulas on-line antes da pandemia e todos afirmaram sentir-se receosos para isso.

Na seção seguinte, as questões trataram de quais suportes os entrevistados receberam para ministrar as aulas no novo formato; era possível marcar mais de uma opção ou adicionar algum tópico próprio com a opção "outros”. Todas as escolas providenciaram algum tipo de suporte aos professores, sendo o apoio pedagógico o mais marcado entre as respostas, (72,7\%), seguido de treinamento técnico para o Ensino Remoto (63,6\%). Nas opções adicionadas pelos participantes, houve a menção do empréstimo de equipamentos e um treinamento para utilizar a plataforma Zoom. Nenhuma das escolas ofereceu auxílio psicológico.

Apesar de as escolas terem ofertado suporte e algum tipo de treinamento técnico e pedagógico, muitos professores demonstraram-se receosos e até mesmo despreparados para realizar o ensino de maneira remota, o que indica que provavelmente o treinamento e suporte não foram suficientes para prepará-los para essa emergência e para a solução das dificuldades que acabaram encontrando durante esses meses. 0 fato de que $54,6 \%$ ainda se encontram no estágio inicial da carreira pode ter contribuído para esses receios.

Em seguida, foram abordadas as dificuldades encontradas pelos professores nas primeiras semanas quando começaram a ministrar as aulas síncronas. Dentre as dificuldades pedagógicas apresentadas aos professores, todos apontaram algum grau de dificuldade com a falta de atenção dos alunos e com as dificuldades dos alunos em lidar com a plataforma usada - Figura 3.

\section{Figura 3: Dificuldades pedagógicas (Parte 1)}




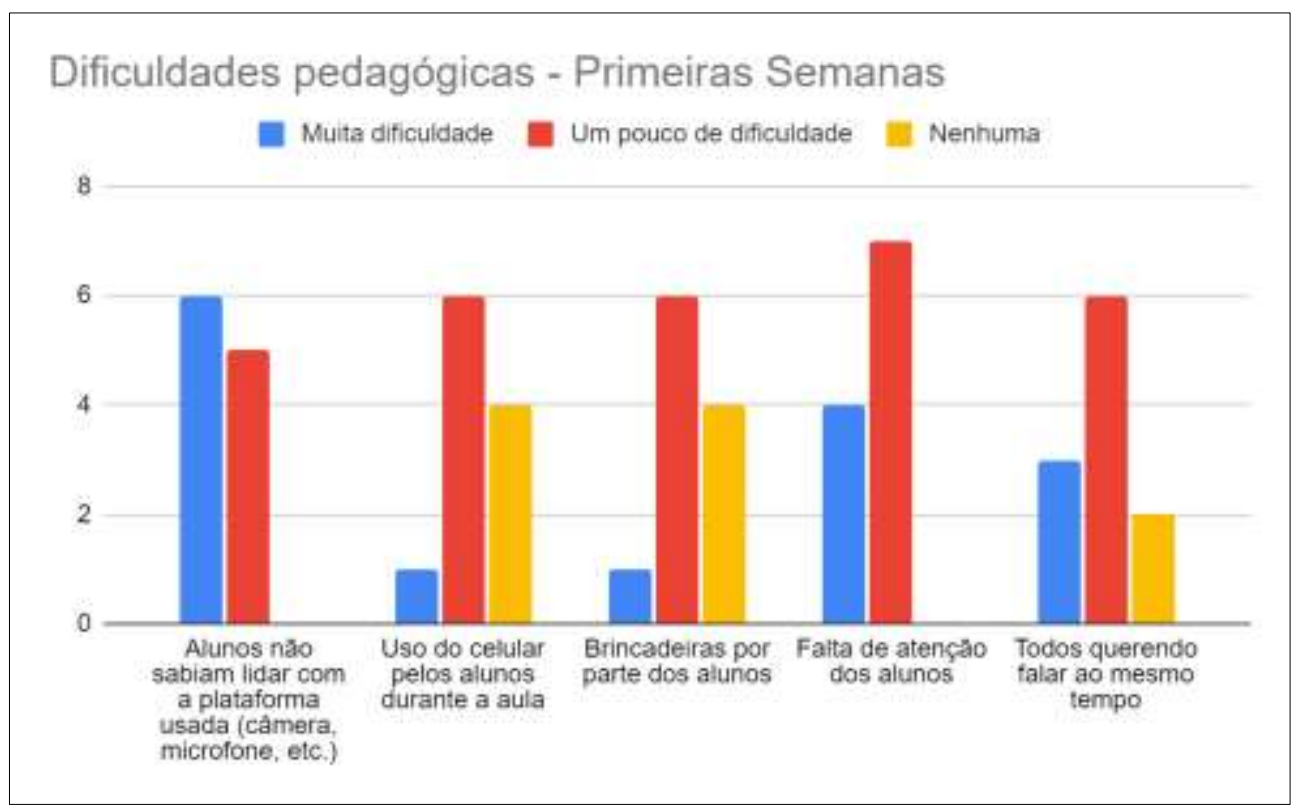

Fonte: Elaborado pelas autoras com base na pesquisa realizada, 2020.

Seis participantes sentiram dificuldade em motivar seus alunos - Figura 4 - e três tiveram alguma dificuldade com a invasão da plataforma por não alunos.

O ERE trouxe mudanças significativas na maneira de dar aula; alguns pontos relatados pelos professores foram positivos para o andamento das aulas, mas negativos para o aprendizado. A distância foi vista como negativa pela ausência do contato e de um ambiente melhor para que as crianças pudessem desenvolver a língua. Alguns participantes apontaram o desinteresse dos alunos em fazer repetições para uma "câmera"; barulhos ou interrupções dos pais; dificuldade em chamar atenção dos alunos de forma discreta ou indicar o andamento das atividades para os alunos atrasados. A distância, entretanto, também trouxe um ponto positivo: sem a proximidade física não há mais conversas paralelas e discussões entre os alunos, o que fez as aulas fluírem. Outro ponto positivo apontado foi o apoio e estímulo visual durante as aulas, que auxiliam a manter a atenção ou trabalhar o conteúdo fora do material didático. Esse apoio não fazia parte da realidade de alguns professores.

\section{Figura 4: Dificuldades pedagógicas (Parte 2)}




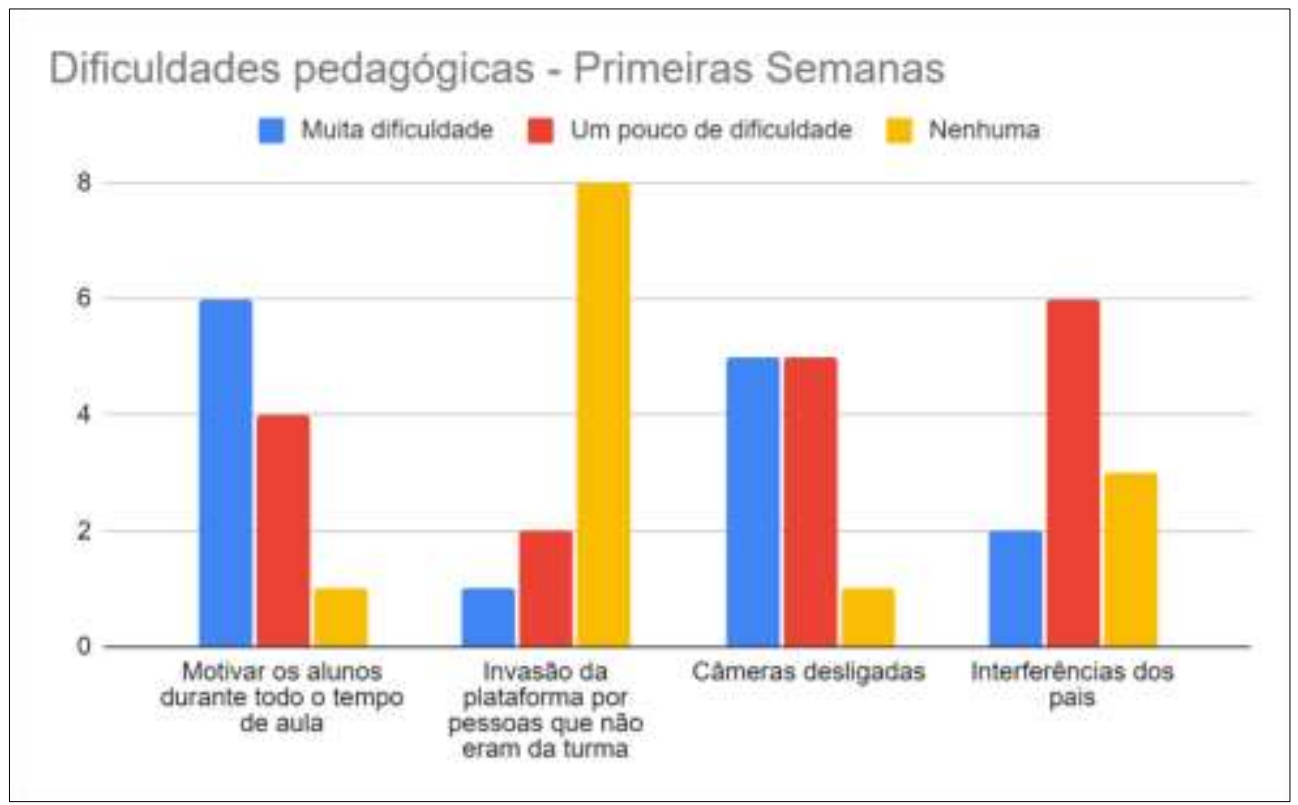

Fonte: Elaborado pelas autoras com base na pesquisa realizada, 2020.

As dificuldades técnicas - Tabela 1 - mais apontadas foram a falta de suporte para problemas técnicos durante as aulas ao vivo e a falta de um local adequado em suas casas. Foi instruído na descrição da pergunta para os participantes que não realizaram aulas síncronas selecionar a opção "não se aplica", o que foi feito por um participante.

Tabela 1: Dificuldades Técnicas

\begin{tabular}{lcc}
\hline $\begin{array}{l}\text { Quais as dificuldades técnicas que você encontrou nas primeiras } \\
\text { semanas de Ensino Remoto (se você deu aulas virtuais síncronas)? }\end{array}$ & $\begin{array}{l}\text { Número } \\
\text { respostas }\end{array}$ & Porcentagem \\
\hline Eu não sabia lidar com a plataforma usada (câmera, microfone, etc.) & 2 & $18,2 \%$ \\
\hline Precisei investir na compra de equipamentos para poder dar as aulas & 3 & $27,3 \%$ \\
\hline Não tinha um local adequado na minha casa para dar as aulas & 4 & $36,4 \%$ \\
\hline Não tinha internet robusta na minha casa, precisei investir nisso também & 0 & $0 \%$ \\
\hline Não tinha internet robusta na minha casa e não pude investir nisso & 0 & $0 \%$ \\
\hline $\begin{array}{l}\text { Eu não tinha computador/notebook/tablet ou qualquer outro } \\
\text { equipamento para usar com meus alunos, só meu celular }\end{array}$ & 2 & $18,2 \%$ \\
\hline $\begin{array}{l}\text { Falta de suporte para as dificuldades técnicas durante as aulas ao vivo } \\
\text { (alguém que eu pudesse contatar e ter resposta imediata) }\end{array}$ & 4 & $36,4 \%$ \\
\hline Não se aplica & & $9,1 \%$ \\
\hline
\end{tabular}

Fonte: Elaborado pelas autoras com base na pesquisa realizada, 2020.

Percebe-se que, exceto pela questão da internet, todos os participantes apontaram alguma dificuldade técnica. Quatro apontaram dificuldade com o espaço adequado, porém isso acaba sendo uma dificuldade que depende da residência de cada um. Também foi apontada a falta de aparelhos como computador, e três precisaram investir nesses equipamentos, enquanto outros três conseguiram usar os aparelhos emprestados pela escola em que trabalham. Apesar disso, as 
dificuldades com a plataforma virtual ou falta de suporte foram mais expressivas. Os professores responderam ter recebido capacitação para o uso das plataformas virtuais, mas isso não garantiu que o acesso e o uso não apresentassem problemas ou eventuais falhas técnicas. A partir disso, é possível analisar que mais de uma capacitação ao longo do ERE, bem como o apoio técnico facilitariam no uso pelos professores, podendo resultar em maior confiança na utilização da tecnologia.

Com relação às dificuldades pessoais - Tabela 2 -, era possível selecionar mais de uma opção como resposta e havia também a opção "não se aplica". Os resultados apontaram que $72,7 \%$ dos professores encontraram dificuldade em lidar com situações inesperadas. A opção "não se aplica" teve 18,2\% de resposta, o que corresponde a 2 participantes; entretanto, quando comparado às respostas sobre as dificuldades técnicas, percebe-se que 1 professor a mais assinalou essa alternativa. Supôs-se que um deles seria o mesmo participante da pergunta anterior que não realizou aulas síncronas, e o outro assinalou essa opção por não ter dificuldades pessoais.

Tabela 2: Dificuldades Pessoais

\begin{tabular}{lcc}
\hline $\begin{array}{l}\text { Quais as dificuldades pessoais que você encontrou nas primeiras } \\
\text { semanas de ensino remoto, se você deu aulas virtuais síncronas? }\end{array}$ & $\begin{array}{l}\text { Número de } \\
\text { respostas }\end{array}$ & Porcentagem \\
\hline $\begin{array}{l}\text { Dificuldade de manter contato visual com meus alunos (aqueles que } \\
\text { deixam as câmeras ligadas) }\end{array}$ & 3 & $27,3 \%$ \\
\hline $\begin{array}{l}\text { Dificuldade para expressar minhas emoções por estar em frente a uma } \\
\text { câmera }\end{array}$ & 3 & $27,3 \%$ \\
\hline Minha própria timidez por estar frente a uma câmera & 2 & $18,2 \%$ \\
\hline $\begin{array}{l}\text { Dificuldade para controlar minha voz por estar usando um microfone (às } \\
\text { vezes muito alta, às vezes alunos não me ouviam) }\end{array}$ & 3 & $27,3 \%$ \\
\hline Dificuldade para lidar com situações inesperadas & 8 & $72,8 \%$ \\
\hline Dificuldade para adotar inovações & 3 & $27,3 \%$ \\
\hline Não se aplica & 2 & $18,2 \%$ \\
\hline
\end{tabular}

Fonte: Elaborado pelas autoras com base na pesquisa realizada, 2020.

Entende-se que as situações inesperadas são diversas, podendo surgir tanto no ambiente em que o aluno está quanto no ambiente em que o professor está. Não há como preparar-se antecipadamente para algumas delas, mas as que aconteceram podem ajudar outros professores. Não foi pedido aos participantes que as descrevessem, mas as escolas podem no futuro solicitar aos seus professores que as reportem e, assim, as dificuldades que enfrentaram e como as solucionaram podem se tornar uma cartilha ou tema de uma capacitação. Dessa forma, os profissionais ficam qualificados para esses momentos e agregam à capacitação inicial.

Outras dificuldades, como timidez, expressão das emoções e contato visual são pontuais de cada indivíduo, mas poderiam ser trabalhadas com um suporte psicológico. Outro fator relacionado às dificuldades pessoais é a saúde mental, que foi afetada devido à pandemia, ocasionando mais estresse, ansiedade e até mesmo depressão (BRASIL, 2020), o que acaba influenciando o desempenho dos profissionais no trabalho. A falta de suporte psicológico pelas 
escolas foi unânime entre os participantes e pode ter contribuído para o sentimento de despreparo e insegurança deles.

\subsection{Estratégias encontradas para o ERE com crianças}

Das estratégias utilizadas pelos participantes, 90,9\% relataram que precisaram alterar sua didática para trabalhar com crianças, e, segundo $81,8 \%$ dos respondentes, o auxílio dos pais foi essencial para o complemento das aulas. Quase metade, isto é, 45,5\% dos participantes acreditam que as dificuldades seriam menores e $36,4 \%$ acreditam que seriam bem menores se as aulas fossem para alunos de uma faixa etária mais avançada.

A estratégia mais utilizada para a elaboração de atividades infantis foi o uso de objetos da casa como brinquedos. Outras estratégias que também foram bastante utilizadas foram o uso de jogos on-line e de filmes ou vídeos, como mostra a Figura 5.

\section{Figura 5: Estratégias utilizadas}

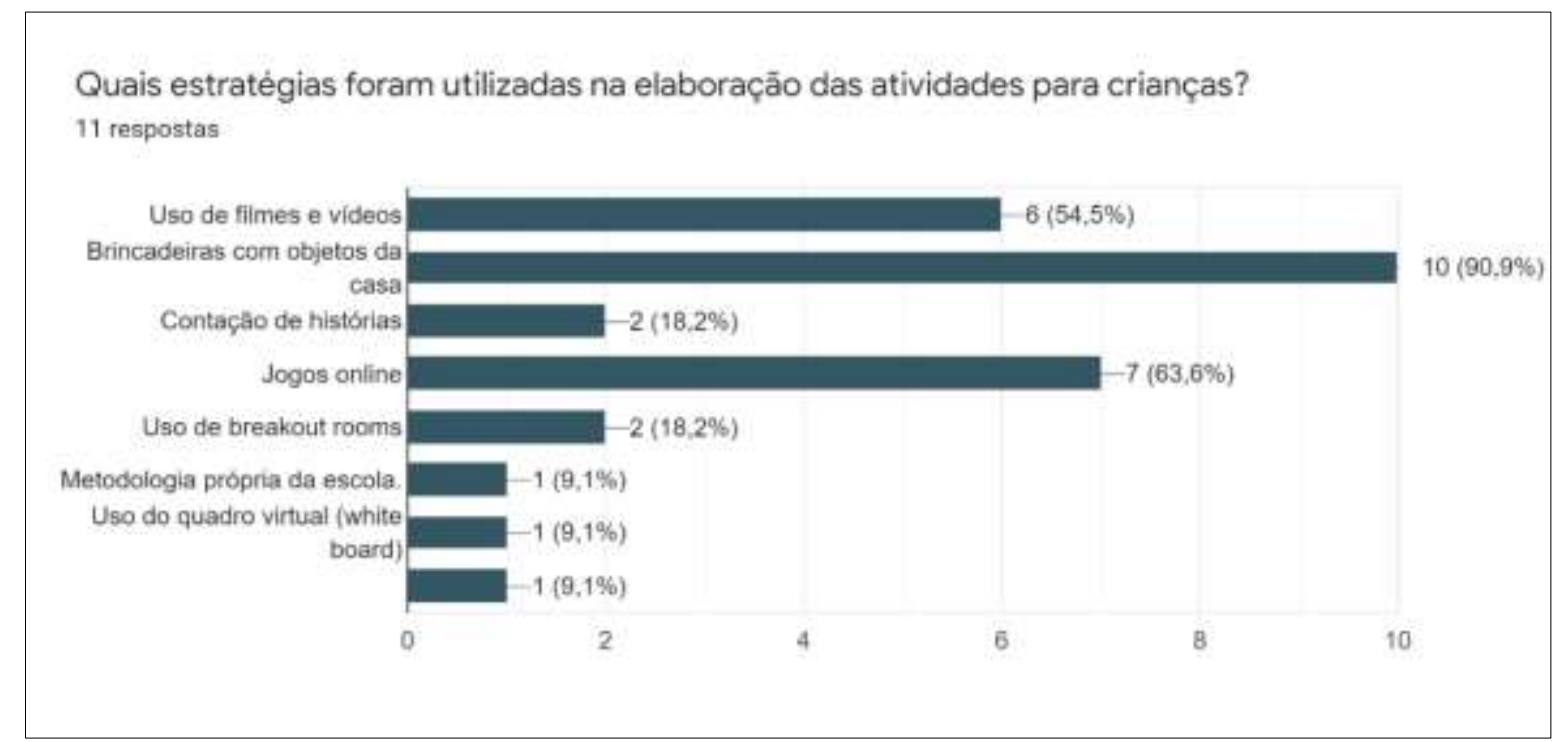

Fonte: Elaborado pelas autoras com base na pesquisa realizada, 2020.

Pode-se inferir que a escolha pelo uso de objetos presentes em casa acontece porque possibilitam uma interação do aluno com o ambiente, saindo do digital e trabalhando com o que se tem em volta, mais semelhante à sala de aula presencial. Mesmo que a maioria tenha relatado o uso de atividades no meio digital, percebe-se que estratégias "tradicionais" como a citada e também a contação de histórias ainda têm seu lugar nas aulas on-line.

Quando perguntados sobre as mudanças mais significativas do Ensino Presencial para o ERE, questão aberta, quatro dos participantes deixaram seus relatos pessoais, apontando o uso da tecnologia, o estímulo visual e o uso de slides como mudanças positivas; ainda relataram como a falta de contato e a diminuição da carga horária dificultaram o processo.

Os participantes também foram questionados sobre a eficácia do ERE, e 45,5\% afirmaram que esse modelo de ensino é eficaz; $27,3 \%$ acreditam que talvez seja eficaz, mas 27,3\% negaram essa eficácia. Os participantes puderam em seguida deixar um comentário sobre a pergunta 
realizada. Dos respondentes, 7 expressaram suas opiniões sobre esse modelo de ensino e comentaram que o ERE deve ser considerado apenas como medida provisória, e não como uma solução definitiva, pois há prejuízos ao ensino-aprendizagem. O que se percebe é que o ERE está servindo ao seu propósito, auxiliando na continuação do ensino em um momento de emergência, mas não é o ideal.

\subsection{O uso da tecnologia no ensino}

Quando questionados em relação ao uso da tecnologia no ensino, 45,5\% dos participantes afirmaram ser difícil o uso da tecnologia no ensino, mas acreditam ser possível uma integração; 36,4\% afirmaram ser fácil a integração, apesar de haver restrições; e 18,2\% acreditam que seja fácil. Nenhum dos participantes afirmou que não é possível realizar essa integração.

Após meses trabalhando com tecnologia, os participantes puderam responder como se sentem, sendo possível marcar mais de uma alternativa. As respostas mostraram que $27,3 \%$ sentiam-se confiantes, $36,4 \%$ preparados e $54,5 \%$ ainda receosos para dar aulas por meio do ERE.

Com a adaptação da tecnologia no âmbito das escolas de línguas, a posição dos professores sobre o seu uso também foi alterada para uma nova perspectiva. A análise das respostas sobre a primeira semana da pandemia e as respostas posteriores sobre as semanas seguintes mostraram uma visão que se pode entender como uma melhora, pois a adequação com as plataformas, ambientes virtuais e aparelhos tecnológicos resultou nessa nova habilidade para os respondentes, demonstrando a possibilidade da inserção efetiva da tecnologia no ensino de línguas.

Parte dos entrevistados encaixava-se na faixa etária entre 19 e 24 anos, o que pode sugerir que a adaptação com a tecnologia desse grupo seja mais fácil que a dos demais, tendo em vista que essa geração cresceu imersa em tecnologia e teria facilidade para lidar e encontrar saídas para situações inusitadas. Esse tipo de inferência, todavia, precisa de aprofundamento.

Com a continuidade do ERE por tempo indeterminado, ocasionando em maior frequência de utilização da tecnologia, poderão ocorrer dificuldades ou aperfeiçoamentos nas habilidades tecnológicas dos professores. Essas possibilidades não foram abordadas neste estudo pelo tempo limitado para a pesquisa.

Ao comparar as soluções encontradas nessas escolas com as alternativas utilizadas em outros países para o ERE é possível afirmar que existem semelhanças. A análise mostrou que as escolas optaram pelo uso de ferramentas on-line, aulas síncronas por meio de plataformas online, aulas assíncronas e AVEAs, o que também foi relatado em outros locais, mesmo que para outros níveis de ensino e não exatamente para escolas de idiomas, conforme visto na seção 3.1 deste estudo.

Para finalizar esta análise, apresentam-se resumidamente as dificuldades encontradas pelos professores durante as aulas do ERE para crianças. Essa verificação abordou três tipos de dificuldades: pedagógicas, técnicas e pessoais. Entre as dificuldades pedagógicas, foram apontadas: a falta de atenção dos alunos, as dificuldades dos alunos em lidar com a plataforma usada, a interferência dos pais, a dificuldade em motivar os alunos, etc. As dificuldades técnicas pontuadas foram: a falta de suporte para os problemas técnicos durante as aulas ao vivo, a falta de um local adequado em suas casas e a necessidade de investir em equipamentos e aparelhos 
tecnológicos. Algumas dificuldades pessoais constatadas podem ser mencionadas: dificuldade para lidar com situações inesperadas, dificuldade de manter contato visual com os alunos, dificuldade para adotar inovações, etc. Como já visto, é possível usar essas vivências para evitar problemas futuros.

\section{CONSIDERAÇÕES FINAIS}

A presente pesquisa buscou analisar as estratégias utilizadas por professores de escolas de língua inglesa de Curitiba nas aulas de ERE durante a pandemia da COVID-19, especificamente para alunos da faixa etária de 06 a 10 anos. Para isso, realizou-se um levantamento sobre o ERE, no qual foi utilizada a definição de Hodges et al. (2020) para a compreensão desse novo período ocasionado pela pandemia. Conjuntamente analisou-se o desenvolvimento do ERE no mundo com base em relatórios desenvolvidos pela UNICEF (2020) e ONU (2020). Buscou-se também conhecer o cenário brasileiro do ensino de línguas e, por fim, a percepção de professores curitibanos, utilizando como base para a criação de um questionário a pesquisa Sentimento e percepção dos professores brasileiros nos diferentes estágios do coronavírus no Brasil (INSTITUTO PENÍNSULA, 2020a; 2020b; 2020c), que relata a situação dos docentes em meio a pandemia.

Os respondentes desse questionário foram professores que trabalham com crianças. Esses alunos demandam a criatividade e habilidades dos profissionais que se encontram em um outro ambiente de ensino. Como resultado, concluiu-se que os professores utilizaram diferentes estratégias e tecnologias para a realização do ERE, tais como AVEAs, continuação do uso do material didático do Ensino Presencial, uso de objetos de casa, aulas síncronas, etc. Muitas estratégias tiveram que ser adaptadas, por ser um outro ambiente sem proximidade física e com o uso da tecnologia. Além disso, o ERE possibilitou aos professores adquirirem novas habilidades ou adaptarem as que já conheciam, o que pode ser proveitoso para o futuro no caso do retorno das aulas presenciais, ou em outros períodos em que seja necessário adotar o ERE novamente. Deve-se destacar que o ERE não é apenas tecnologia e que, diferente das escolas estudadas, em outros contextos essas estratégias não são uma opção.

Entende-se que esse processo incentivou o emprego da tecnologia nas escolas de línguas. Para aquelas que já utilizavam, foi uma nova maneira de ampliar as possibilidades de uso; para as que não usavam, o ERE se mostrou como um elemento de incentivo para a integração. Em conjunto a isso, ficou explícita uma mudança de opinião sobre a tecnologia. Ainda assim, não foi possível mensurar se essa mudança aconteceu de maneira positiva ou negativa, pois não foram feitas perguntas específicas.

A ausência de certas interferências que ocorrem na modalidade presencial, como as conversas paralelas e discussões entre os alunos, foram pontos mencionados pelos professores, mas isso não impediu que houvesse outras interferências externas em suas próprias casas, como os pais observando as aulas o tempo todo.

Apesar dos pontos positivos mencionados acerca do ERE nas escolas de línguas onde os entrevistados atuam, percebe-se que essa medida ainda precisa de aprimoramento para atender às demandas e que deve funcionar apenas como algo provisório, não efetivo, fazendo jus à sua utilização em casos extraordinários e emergenciais. Ficou evidente que mais capacitações para o uso de tecnologia no ambiente educacional e aprimoramentos dos AVEAs são necessários para 
que o regime de ERE possa funcionar de maneira mais proveitosa. Especialmente em escolas de idiomas que, para se manter em funcionamento, precisam continuar com suas aulas ou correm o risco de verem seus alunos cancelando matrículas.

A pesquisa realizada teve limitações, algumas já destacadas anteriormente. As principais foram: o pouco tempo para a sua realização, a falta de dados sobre o total do público-alvo e o funcionamento das escolas de línguas, já que não há um órgão que reúna essas informações. Além disso, havia naquele momento escassez de produções acadêmicas para maior fundamentação teórica e as informações mais relevantes e que envolviam a condição dos professores naquele período eram sobre o ensino regular. A questão da dificuldade de se determinar o número de professores que atuam em escolas de línguas surge como ponto de destaque. Esse é um contexto que deve ser pesquisado, são muitos os profissionais que ali atuam, mas, como se verificou, não é possível obter-se o total dessa população. Essa é, portanto, uma demanda que precisa ser atendida por estudiosos na área. Isso gerou resultados limitados, mas que podem ser um auxílio para futuras pesquisas, especialmente sobre o contexto das escolas de idiomas.

Com mais tempo, trabalhos sobre o tema podem obter mais dados e incluir mais aspectos, como saber a maneira que o ERE ocorreu em outras cidades ou em outros níveis educacionais. A atual pesquisa pode ser usada como um teste piloto para esses futuros estudos. É possível reaplicar a pesquisa em Curitiba para um número maior de respondentes e assim aprofundar os resultados e abranger também o período pós-pandemia, fazendo uma comparação entre o que foi realizado no ERE e o que se manteve.

Por fim, não se sabe quando a pandemia da COVID-19 acabará, podendo ser nos próximos meses ou não, e também há a possibilidade de outras pandemias (BBC NEWS BRASIL, 2020), o que pode demandar novamente o ERE. Com a experiência atual, as escolas poderão se preparar melhor para essa possibilidade e entender quais foram os erros e acertos. Assim, mesmo que em uma escala pequena, a presente pesquisa terá contribuído para isso.

\section{REFERÊNCIAS}

ANSCOMBE, T. Proteja nossas crianças e jovens. AVG, 2014. Disponível em: https://crianca.mppr.mp.br/arquivos/File/publi/internet/avg_ebook.pdf. Acesso em: 22 out. 2020.

ASSOCIAÇÃO BRASILEIRA DE FRANCHISING (ABF). Franquias de Serviços Educacionais. 2021. Disponível em: https://franquias.portaldofranchising.com.br/franquias-de-servicos-educacionais/. Acesso em: 02 set. 2020.

BANCO MUNDIAL. Políticas Educacionais na Pandemia da Covid-19: O que o Brasil pode aprender com o resto do Mundo?. 2020. Disponível em:

http://pubdocs.worldbank.org/en/413781585870205922/pdf/POLITICAS-EDUCACIONAIS-NA-PANDEMIADA-COVID-19-O-QUE-O-BRASIL-PODE-APRENDER-COM-O-RESTO-DO-MUNDO.pdf. Acesso em: 12 ago. 2020.

BBC NEWS BRASIL. Por que uma nova pandemia nos próximos anos é praticamente inevitável. 2020. Disponível em: https://www.bbc.com/portuguese/geral-53758807. Acesso em: 17 ago. 2020. 
BLIKSTEIN, P. et al. Como estudar em tempos de pandemia. 2020. Disponível em:

https://epoca.globo.com/como-estudar-em-tempos-de-pandemia-24318249. Acesso em: 02 set. 2020.

BRASIL. Lei n 9.394, de 20 de dezembro de 1996. Lei das Diretrizes e Bases da Educação Nacional. Estabelece as diretrizes e bases da educação nacional. Diário Oficial da União: seção 1, Brasília, DF, p. 27933, 23 dez. 1996. Disponível em: http://www.planalto.gov.br/ccivil_03/LEIS//9394.htm. Acesso em: 10 set. 2020.

BRASIL. Decreto n 9057 , de 25 de maio de 2017. Regulamenta o art. 80 da Lei n 9.394, de 20 de dezembro de 1996 , que estabelece as diretrizes e bases da educação nacional. Diário Oficial da União: seção 1, Brasília, DF, p. 3., 26 mai. 2017. Disponível em: http://www.planalto.gov.br/ccivil_03/_ato20152018/2017/decreto/d9057.htm. Acesso em: 06 abr. 2021.

BRASIL. Ministério da Saúde. Fundação Oswaldo Cruz. Saúde Mental e Atenção Psicossocial na Pandemia COVID-19: recomendações gerais. Brasília: MS/FIOCRUZ, 2020. Disponível em: https://www.fiocruzbrasilia.fiocruz.br/wp-content/uploads/2020/04/Sa\%C3\%BAde-Mental-eAten\%C3\%A7\%C3\%A3o-Psicossocial-na-Pandemia-Covid-19-recomenda\%C3\%A7\%C3\%B5es-gerais.pdf. Acesso em: 14 out. 2020.

BRASIL. Ministério da Educação. MEC orienta instituições sobre ensino durante pandemia. 2020. Disponível em: https://www.gov.br/pt-br/noticias/educacao-e-pesquisa/2020/06/mec-orientainstituicoes-sobre-ensino-durante-pandemia. Acesso em: 21 ago. 2020.

DEREVECKI, R. Seu filho está desanimado com as aulas online e tem saudade da escola? Saiba como ajudá-lo. 2020. Disponível em: https://www.semprefamilia.com.br/educacao-dos-filhos/seu-filhodesanimado-aulas-online-saudade-escola-saiba-como-ajuda/. Acesso em: 22 out. 2020.

ESCOLAS EXPONENCIAIS. Como as escolas ao redor do mundo têm lidado com a suspensão das aulas?. 2020. Disponível em: https://escolasexponenciais.com.br/tendencias-e-metricas/como-as-escolas-aoredor-do-mundo-tem-lidado-com-a-suspensao-das-aulas/. Acesso em: 03 set. 2020.

FARIAS, M. S. et al. Ensino remoto e tecnologia: uma nova postura docente na educação pós-pandemia. In: CONGRESSO NACIONAL DE DUCAÇÃO, 7., 2020, Maceió. Anais eletrônicos [...]. Campina Grande: Realize Editora, 2020. Disponível em: https://editorarealize.com.br/artigo/visualizar/68528. Acesso em 18 nov. 2020.

GALLAS, D. Coronavírus na escola: o que diz a ciência sobre os riscos da volta às aulas?. 2020. Disponível em: https://www.bbc.com/portuguese/geral-53681929. Acesso em: 13 ago. 2020.

GAROFALO, D. 0 que esperar da educação pós-pandemia. 2020. Disponível em: https://www.uol.com.br/ecoa/colunas/debora-garofalo/2020/05/13/o-que-esperar-da-educacao-pospandemia.htm. Acesso em: 18 nov. 2020.

GIL, A. C. Como elaborar projetos de pesquisa. 4. ed. São Paulo: Atlas, 2002.

GRATÃO, P. Coronavírus: Com aulas online, escolas de idiomas driblam evasão e conquistam novos alunos. 2020. Disponível em: https://revistapegn.globo.com/apoie-o-negocio-

local/noticia/2020/04/coronavirus-com-aulas-online-escolas-de-idiomas-driblam-evasao-e-conquistamnovos-alunos.html. Acesso em: 02 set. 2020.

HODGES, C. et al. The Difference Between Emergency Remote Teaching and Online Learning. 2020. Disponível em: https://er.educause.edu/articles/2020/3/the-difference-between-emergency-remoteteaching-and-online-learning. Acesso em: 21 ago. 2020. 
INSTITUTO PENÍNSULA. Sentimento e percepção dos professores brasileiros nos diferentes estágios do Coronavírus no Brasil: março de 2020. 2020a Disponível em: https://institutopeninsula.org.br/wpcontent/uploads/2020/05/Pulso-Covid-19_-Instituto-Peni\%CC\%81nsula.pdf. Acesso em: 02 set. 2020.

INSTITUTO PENÍNSULA. Sentimento e percepção dos professores brasileiros nos diferentes estágios do Coronavírus no Brasil: estágio intermediário - maio de 2020. 2020b. Disponível em:

https://www.institutopeninsula.org.br/wp-

content/uploads/2020/05/Covid19_InstitutoPeninsula_Fase2_at\%C3\%A91405-1.pdf. Acesso em: 02 set. 2020.

INSTITUTO PENÍNSULA. Sentimento e percepção dos professores brasileiros nos diferentes estágios do coronavírus no Brasil: estágio controlado - agosto de 2020. 2020c. Disponível em: https://www.institutopeninsula.org.br/wp-content/uploads/2020/08/Sentimentos_-fase-3.pdf. Acesso em: 02 set. 2020.

JOHNS HOPKINS. COVID-19 Dashboard by the Center for Systems Science and Engineering (CSSE) at Johns Hopkins University (JHU). 2020. Disponível em: https://coronavirus.jhu.edu/map.html. Acesso em: 20 ago. 2020.

JOYE, C. R.; MOREIRA, M. M.; ROCHA, S. S. D.. Educação a Distância ou Atividade Educacional Remota Emergencial: em busca do elo perdido da educação escolar em tempos de COVID-19. Research, Society and Development, v. 9, n. 7, p. e521974299-e52197429, 2020. Disponível em:

https://rsdjournal.org/index.php/rsd/article/view/4299/3757. Acesso em: 07 abr. 2021.

MARTINS, C. B. M. J.. Fatores que influenciam a aceitação da Internet como ferramenta educacional nas escolas de línguas de Curitiba. 2002. Dissertação (Mestrado em Engenharia de Produção) Programa de

Pós-Graduação em Engenharia de Produção, Universidade Federal de Santa Catarina, Florianópolis, 2002. Disponível em:

https://repositorio.ufsc.br/xmlui/bitstream/handle/123456789/82674/195119.pdf?sequence=1\&isAllowed =y. Acesso em: 20 ago. 2020.

MOREIRA, H.; CALEFFE; L. G. Metodologia da pesquisa para o professor pesquisador. Rio de Janeiro: DP\&A, 2006.

MOREIRA, H. Motivation profiles of physical education teachers. 1995. Tese (Doutorado) - University of Exeter, Exeter, Great Britain, 1995.

NÚCLEO CIÊNCIA PELA INFÂNCIA (NCPI). Repercussões da Pandemia de COVID-19 no Desenvolvimento Infantil. São Paulo: Fundação Maria Cecilia Souto Vidigal, 2020. Disponível em: https://ncpi.org.br/wpcontent/uploads/2020/05/Working-Paper-Repercussoes-da-pandemia-no-desenvolvimento-infantil3.pdf. Acesso em: 21 ago. 2020.

ORGANIZAÇÃO DAS NAÇÕES UNIDAS (ONU). Policy Brief: education during covid-19 and beyond. United Nations Sustainable Development Group, 2020. Disponível em: https://unsdg.un.org/resources/policybrief-education-during-covid-19-and-beyond. Acesso em: 09 set. 2020.

ORGANIZAÇÃO MUNDIAL DA SAÚDE (OMS). Timeline: WHO's COVID-19 response. 2020. Disponível em: https://www.who.int/emergencies/diseases/novel-coronavirus-2019/interactive-timeline\#event-72. Acesso em: 20 ago. 2020.

PARANÁ. Secretaria Estadual de Educação. Aula Paraná segue o modelo ideal recomendado pela Unesco. 2020. Disponível em: 
http://www.aen.pr.gov.br/modules/noticias/article.php?storyid=106799\&tit=Aula-Parana-segue-omodelo-ideal-recomendado-pela-Unesco-. Acesso em: 21 ago. 2020.

SOCIEDADE BRASILEIRA DE PEDIATRIA (SBP). Grupo de Trabalho Saúde na Era Digital. Manual de Orientação: menos telas, mais saúde. 2019. Disponível em:

https://www.sbp.com.br/fileadmin/user_upload/_22246c-ManOrient_-_MenosTelas__MaisSaude.pdf. Acesso em: 19 out. 2020.

ORGANIZAÇÃO DAS NAÇÕES UNIDAS PARA A EDUCAÇÃO, A CIÊNCIA E A CULTURA (UNESCO). UN Secretary-General warns of education catastrophe, pointing to UNESCO estimate of 24 million learners at risk of dropping out. 2020. Disponível em: https://en.unesco.org/news/secretary-generalwarns-education-catastrophe-pointing-unesco-estimate-24-million-learners-0. Acesso em: 13 ago. 2020.

FUNDO INTERNACIONAL DE EMERGÊNCIA DAS NAÇÕES UNIDAS PARA A INFÂNCIA (UNICEF). COVID-19: Are children able to continue learning during school closures?. New lork: UNICEF, 2020. Disponível em: https://www.unicef.org/brazil/media/10006/file/remote-learning-factsheet.pdf. Acesso em: 03 set. 2020.

WALKER, S. The Landmark Review of English language Teaching in Brazil. Brasília, dez. 2005.

Disponível em: https://docplayer.net/52344284-The-landmark-review-of-english-language-teaching-inbrazil.html. Acesso em: 03 set. 2020. 